\title{
A Japanese Approach to Haptic/Multimodal Art Practice and Perception
}

\author{
EMILIA SOSNOWSKA \\ University of the West of Scotland
}

\begin{abstract}
This paper reflects a fraction of research which sets out to examine the complex constructions and debates underpinning visual culture theory, and assesses its adequacy as the main theoretical framework with which to engage in contemporary interactive art. The treatment presents digital art in Japan with its roots in traditional East Asian philosophy giving the senses a prominent role in perceiving the world and enabling perfect symbiosis between humans and machines. This paper points out the expansion of this culturally and traditionally inspired spirituality from its natural and cultural context to contemporary digitally mediated environments. This is accomplished through an analysis of digital interactive work by specific artists located in Japan, such as Kumiko Kushiyama, Masaki Fujihata and Ryota Kuwakubo.
\end{abstract}

\section{KEYWORDS}

Beyond visual, Multisensory experience, Digital media, Device Art.

\section{Introduction}

There are many takes on visual culture theory and attempts to apply it to new media art in a broadened context. One of the most important figures in visual culture theory is Lev Manovich, who takes into consideration the concept of interactivity and its significance in today's art and art history. Moreover, through the acknowledgement of new media art and its role in art practice, he notices a lack of theoretical continuum between strictly or predominantly visual art, such as paintings, and multisensory art, such as interactive installations (2003). Nevertheless, the subject of multisensory experiences has been considered in an anthropologist/cultural (anthropology of the senses) approach to the theme. Constance Classen scrutinises the sensory perception as a cultural, as well as a physical act, noticing that tactile sensations, similar to any other occurrences of our sensory nature, convey cultural values on top of purely physical attributes (1997). In fact, the world is perceived through the senses and sensory perception is based on cultural construction. Referring to Karen Cham (2009), aesthetic value is culturally coded, which is why by the complexity of various factors it can either be highly appreciated or ignored.

Accordingly, since people's perception is traditionally connected with human evolution, the fact that 
nowadays culture is based on sensing and perceiving reality through all equally important senses cannot, and indeed should not, be ignored. In visual culture theory, there have been attempts to convey more interdisciplinary approaches, including human senses. One of the theoreticians who undertook this challenge was Walter Benjamin, who stressed that "during long periods of human history, the mode of human sense perception changes with humanity's entire mode of existence. The manner in which human sense perception is organised, the medium in which it is accomplished, is determined not only by nature but by historical circumstances as well" (1969 [1936]). Applying this statement to today's reality, one notices that the media of the present certainly concern all human senses and are based on the very concept of sensory language. This, in consequence, induces alternative methods of dealing with sensory perception of interactive art within the visual or alternatively multisensoryldigital culture theory. In reference to Mieke Bal, the appropriate modus operandi is needed for the particular phenomenon: "[i]f the tasks of visual culture studies must be derived from its object, then, in a similar way, the methods most suitable for performing these tasks must be derived from those same tasks, and the derivation made explicit" (Bal 2003).

However, very few thinkers predicted such a quick succession of new scientific ideas and immediate responses from engineers to the prompt technological innovations. In consequence, a whole new range of experiences must be taken into consideration in this theoretical debate. In interactive art, physicality and the intentional action generates a certain sensation and bodily experience. In times of digital culture, the hierarchy of the senses shifts, which means that auditory or tactile experiences are becoming equally important in the process of communication, connectivity or perception. One can clearly see the effects of this expanded force of perception in today's world, not only in novel military applications, but also in everyday devices such as vibrating mobile phones, or e-books, among other tangible tools. Nonetheless, clear boundaries between individual senses are blurring into one sensory experience (McLuhan 1964). As long as contemporary culture rejects or underestimates the multisensory nature of human perception, the challenge to propose media technological culture theory remains tremendous.

\section{Japanese context}

The contribution of Japanese electronic media artists plays a significant role in today's digital media art. The potential of art created in an Asian context is acknowledged in works by various new media art scholars, such as Lev Manovich (2003), Marshall McLuhan (1998), or Ryszard Kluszczynski (2010). While Manovich observes that Japan has a strong voice in the digital media debate, McLuhan refers to the Japanese approach to technology inspired by Zen Buddhism, and Ryszard Kluszczynski elaborates on an instrument strategy, relating it to 'Device Art'.

The presence of the Japanese artists related to the new media scene has been evident since the growth of the digital media environment. Major international festivals in Europe, the most established being Ars Electronica in Linz, Austria, or SIGGRAPH organized across the United States and Asia, are the main events bringing together digital media artists and theorists from the Western, as well as the Eastern, corners of the world. Accordingly, names of artists, such as Toshio Iwai or Masaki Fujihata, are internationally renowned and recognized also outside Japan. Paradoxically, media art discourse reflects almost exclusively on the Western perspective. There has been relatively little theoretical debate with literature in the field, limited to just a few names and writings. As such, the most prominent voices in 
the discourse belong to Mashiko Kusahara (a scholar in media art, digital media culture and media history), Hiroshi Yoshioka (a scholar of aesthetics and art theory), Tomoe Moriyama (a curator of visual media, art and technology) and Mauro Arrighi (a new-media artist, lecturer and independent-curator). In short, Kusahara introduced the notion of Device Art to international attention, Yoshioka comments on the concept of media art in the West and Japan, Moriyama shares her perspective on the Japanese media art scene, and Arrighi contributes to a debate on Japanese media art and animism. Furthermore, the Japanese context and hybridised approach to digital art in Japan has been undertaken by Yvonne Spielmann (2012) and a cross-cultural debate on media and technology presented by Erkki Huhtamo (2007).

Literature concerning multi-sensory and the tactile perception of interactive art, on the other hand, illustrates the subject mainly in the media-technological, or strictly scientific, context. As such, it is discussed primarily in works by researchers such as Hiroshi Ishii, Gabriel Robles-De-La-Torre, Angela Chang, Conor O'Sullivan and Brenda Laurel. Ishii founded the Tangible Media Group with the main focus on designing seamless interfaces for Human Computer Interaction; Robles-De-La-Torre undertakes extensive research on the sense of touch and haptic perception, focusing on the haptic perception of shape; Chang and O'Sullivan work on haptic visualisation and the multisensory aspects of digital media using sound vibration. Lastly, interactive media researcher Brenda Laurel engages with human-computer interaction design and interactive narratives since 1976.

Looking at interactive media artworks, I would like to present a culturally specific and critical perspective on digital creativity, including the spectrum of human sensory features. Referring to writings by thinkers such as Machiko Kusahara, Tomoe Moriyama and Yvonne Spielmann, among others, the following section presents some Japanese beliefs and rituals, in order to provide an aesthetic view of digital media art in the wider perspective of East Asia, and Japan in particular.

\section{Tradition}

Outlining the background for artistic practices adopting technology and interactive interfaces, and considering the historical background of the aforementioned, we need to take into account a notable uniqueness of Japanese philosophical thought. Japanese culture with its foundation in the East Asian philosophical tradition, monism of body and mind connected with Zen Buddhism and Shinto ideology, gives the senses a prominent role in perceiving and experiencing the world. Eastern philosophy implies that between the subjects and the object, as well as mind and body, exists a relationship which induces harmony, and the human being is treated as a complete organism, unified in mind and body. Sociologist, Shmuel Noah Eisenstadt, differentiates five main characteristics regarding Japanese ontology, among which I refer to: the everyday world implicated with the transcendent, as well as 'cosmic and natural orders of things, where 'culture' and 'nature' are connected in harmonic symbiosis' (Bruun and Kalland 1995).

By means of interactive technology, certain aspects of art have gone through a transformation: some new tools have been developed; creative collaborations have brought together art and technology; artists and engineers often team up with big companies and on account of their funding, implement their prototypes. Nevertheless, the fact that Shinto remains a source of influence on current Japanese electronic art is being confirmed by artists and intellectuals who declare their inspiration deriving from the body of Japanese traditions comprising Shinto belief. Academics such as Moriyama, Kusahara or 
Yoshioka stress this notion in their writings concerning contemporary research in art (Moriyama 2006, Kusahara 2001, Yoshioka 1997).

Charged with reasoning, Shinto belief has its foundation in the ancient heritage. This tradition in Japan asserts 'existence of spiritual life in objects or natural phenomena called $m i$ (the god) and tama (the spirit)' (Kitano 2006, 1). Many theoreticians of contemporary art in Japan refer to Shintoism as being one of the main sources of influence on Japanese sensibility (Arrghi 2011, Kitano 2006, and more tentatively Kusahara 2013). It pertains to the relation with nature as well as inanimate objects, including machines and other electronic devices. Shinto, being a polytheistic and animistic belief, is the earliest form of religion known in Japan. It is a certain construct, influenced by a religion-like folk attitude, which manifests belief in the 'existence of "spirit" not only in organisms but also in their living environments (...). Everything can have a spirit, and these collective spirits are known as Kami, in which man, nature, and even the gods, impartially constitute the whole' (Chow 2012, 181). It indicates the existence of deities in all the natural forces, as well as their manifestations. Kami can be found anywhere, where all the natural elements exist; from the mountains, streams and oceans, to the moon and the sun. Accordingly, while describing Shintoist beliefs, one can say that its characteristics refer to ancient rituals related to nature, where on the other hand any everyday objects are attributed with magical and supernatural powers. Even in contemporary Japan, a society which is highly automatized and remarkably systematized, belief in the existence of spirits is present in everyday life (Kitano 2006).

The creative arts in Japan are greatly inspired by nature and although they are not trying to recreate or imitate it, artworks often convey its essence. This tendency reaches beyond areas of artistic creativity and design, and is reflected in other spheres like interior design, fashion, or music. Moreover, this inclination includes technologically aided works of art which correspond with the symbiosis between human and nature noted above as well as ideology related to spirituality of all matter. This holistic view of life also prevails in the perception of artefacts. Consequently, the majority of Japanese religions incorporate a non-dualistic approach and elements of animism (a view that sees spirit in every component of the world, not only human beings). Referring to Kenny KN Chow (2012), I suggest that this culturally and traditionally inspired spirituality is transposed from natural or cultural environments to a present day technological environment of sophisticated multimedia devices and tools used widely in interactive art and digitally mediated environments. Moreover, in a multimodal environment, interaction enables multisensory experience and is greatly interwoven with the fluidity of aesthetic experience. All of the discussed examples refer to physical engagement with artworks and enable sensory involvement.

Contemporary Japanese media culture has its own history and tradition, which largely influences its approach to technology, media and the perception of art. The East Asian backgrounds of the artists embedded in today's technologically inspired context, clearly represent evidence and tendencies which exemplify some of the ideas of East Asian religion and teachings. Digital interactive artworks are able to embrace Asian adaptation of a holistic approach to life and nature. Japanese animism, whether intentional or not, is often mirrored in artistic creations, as some of the chosen examples demonstrate: Kushiyama's creature-like, tactile, furry interfaces, or nature-inspired references in works by Fujihata, among others.

Since most of the world's innovative developments, such as applications of virtual reality, and wearable and wireless systems, can be traced back to military research, it is the main ground on which social 
growth and the progress of new technologies are tested and verified, and only afterwards extended into other areas of human activity. According to Kusahara (2013), in the West there is a negative connotation of technology, mainly due to the social and physical impact of the industrial revolution, predisposing westerners to perceive robots and machines as horror figures. Analogies of the dark vision can be traced to works such as Fritz Lang's Metropolis, or Karl Čapek's R.U.R., where the author introduced the word robot in a negative way, projecting a general trend towards dystopian visions of new technology. Another factor in creating an antipathy to such technological innovations is their potential for military application (Daniels 2008). The above considerations are strictly connected to the way the Western society associates, and perceives - often unconsciously - technological innovations. Specific distance and often discernible skepticism seems to be justified and remains in contrast to the Eastern world, especially Japan, where historically, the main focus has been on rapid industrialisation, mainly in the political period of Meiji Restoration 1868-1912. The whole country went through a modernisation process, which could not be gradually introduced as a natural progression. On the contrary, it was enforced and popularised by the government. An important fact is also that Japan is one of the very few non-Western countries which was never colonised. Partly on account of its geographical location, Japan was naturally disconnected from major influences likely to arrive from dominant and leading countries. Further, as a result of Japan's feudal past, for over 250 years it was isolated from the Western world and after the opening of its boundaries, technological development had a chance to grow at a rapid pace (Yamaguchi, 2002). Technology in Japan has always been perceived as a central theme of creative development (Kusahara 2002), as well as being a widely acknowledged tool in the hands of an artist. As such, it is treated as a positive phenomenon by the majority of artists and people living in Japan.

\section{Japanese electronic art and Device Art movement}

Technological development has always been a great inspiration for human beings and a factor of progress and new experiences. In Japan, extensive research on novel technologies and their creative use has inter alia resulted in the notion of Device Art. Hiroo Iwata, engineer and artist, started experimenting with haptic interfaces in 1989, and in 2004 initiated the Device Art Project. The idea for the title of the project 'Device Art' derived from Iwata's research activities and blended media art and interactive technologies. The name itself was inspired by Ryuta Kuwakubo - discussed later in the text - who once called himself a device artist. Device Art had been developed as a research project and has since evolved into an art movement. Its principal characteristics indicate the use of mechatronic devices, new materials and the convergence of novel technologies, art and design. Artists using everyday components mix them together with the most recent technologies creating artworks in the form of devices (Kusahara 2008). According to Japanese scholars, the above concept reconsiders relationships between science, technology and art, taking into account historical as well as contemporary perspectives. As such, this form of media art combines art and technology with popular culture, design and playfulness.

The concept of Device Art is conceived as a modern take on traditional Japanese culture. By openness to developments in technology, the possibilities given by new materials as well as the acceptance of very fluid borders, or rather the lack of borders, it blends amusement, art, technology, design and popular culture. Kusahara - one of the principal Japanese theorists and curators of new media art underlines the determining role of technology, in relation to media artists in Japan: "New technology has been, and is used, to discover new forms of entertainment and to promote communication through 
it. Art, entertainment and everyday life are continuous both in terms of concept and visual design" (2001). This approach is presented in one of the subsequent examples in the text. Furthermore, in a similar critical stance developed by Mauro Arrighi (2011), the artist and researcher argues that the religious basis present in Japanese culture is an essential element that underpins the development and popularisation of new media art in its specific forms of hybrid art and Device Art in Japan. Lastly, theoreticians such as Mariyama and Kusahara, among others, repeatedly refer to the historical foundations on which their work is built, including ancient religious beliefs, folk culture and linguistic structure, as a significant determinant of the characteristic approach these artists have developed.

While some of the artists use new technologies as a tool assisting with the design of the project, for others it is a medium which carries aesthetic values and enriches participants' experience. Nevertheless, what all of them share is that they represent a current of digital art which routinely deploys multimodal technological devices. All of the works presented here serve as practical examples of the potential for embodied experience and multisensory engagement with an artwork. They illustrate particular aspects of interactive artwork, such as individual artistic strategies used in their production, the processes involved, modes of participatory engagement, and the potential avenues and opportunities they present for bodily experience.

\section{Sensory engagement through particular examples}

All of the works further discussed in this paper are systems enabling the manipulation of various processes which, in consequence, provide the means for sensory engagement. Each of the works demonstrate a variety of applications and stands, yet constitute the extensive array of artistic representations which in their aesthetic perspective take into account human senses in art perception. The range of artists presented in this paper range from those who started experimenting with technological devices in the early $80 \mathrm{~s}$ - such as Masaki Fujihata - to those who are specifically focused on a particular sensory feature - such as Kumiko Kushiyama's focus on the sense of touch - to Ryota Kuwakubo, for whom the multimodality of an object determines spectators' or users' multi-sensory experience, and who exemplifies the Device Art movement.

All of them challenge the classic artist-artwork-audience relationship (see Ascott 1966), and are part of the notion of a paradigm shift from the art object to multi-sensory experience. It is also appropriate to characterize two different sides of bodily engagement: the body, as a foundation of immersive experiences, and processes of the cognitive interpretation of interaction and immersion (Siemanowski, 2010).

The first artist that this paper refers to is Ryota Kuwakubo, a digital artist and a pioneer of the Device Art movement. At the beginning of his career he had been working on electronic toys. The artist's initial fascination was chiefly related to actuators and sensors. The first works that he created were not considered art objects, but rather electronic devices and games. Throughout the years his creative explorations have led to projects which have a more critical character, but nevertheless are grounded in the Device Art notion. The following work Nicodama (2009) is an interface in the form of two half spheres, resembling hyper-realistic eye balls. The participant is invited to lift the 'eyeballs' and place them freely in the space. The only limitation in order for the work to function is that both small handheld devices need to be arranged in a straight line - just like ordinary eyes. 
The work is comprised of a small transceiver based on an infrared principle. On account of a magnetic mechanism installed at the back of the work, Nicodama can be aligned anywhere in the space. To interact with the artwork the devices need to be held and accordingly actuated by the participant, giving the user control over an animated creature, thus enabling physical engagement. In the text accompanying the Device Art exhibition, the artist refers to Japan's historical past and that people "felt [that] each of the objects around them had a spirit, and treated them with respect and care. Today we share a more objective and scientific approach in seeing things. While there is no doubt that it is important to maintain this attitude, the capacity for empathy is equally important" (Kuwakubo 2009). The blinking pair of 'eyes' react to the participant's engagement and only by physical interaction can perform as a completed work. This object, along with some other works by Kuwakubo, are available as a commercial product, proving to be one of the examples of blurred boundaries between art and entertainment in Japanese culture. Production of gadgets and toys by artists is a common practice in Japan (Kusahara, 2006). This does not exclude those digital devices from being shown within art galleries as well as being mass produced by large companies and exhibited during art fairs or in commercial spaces.

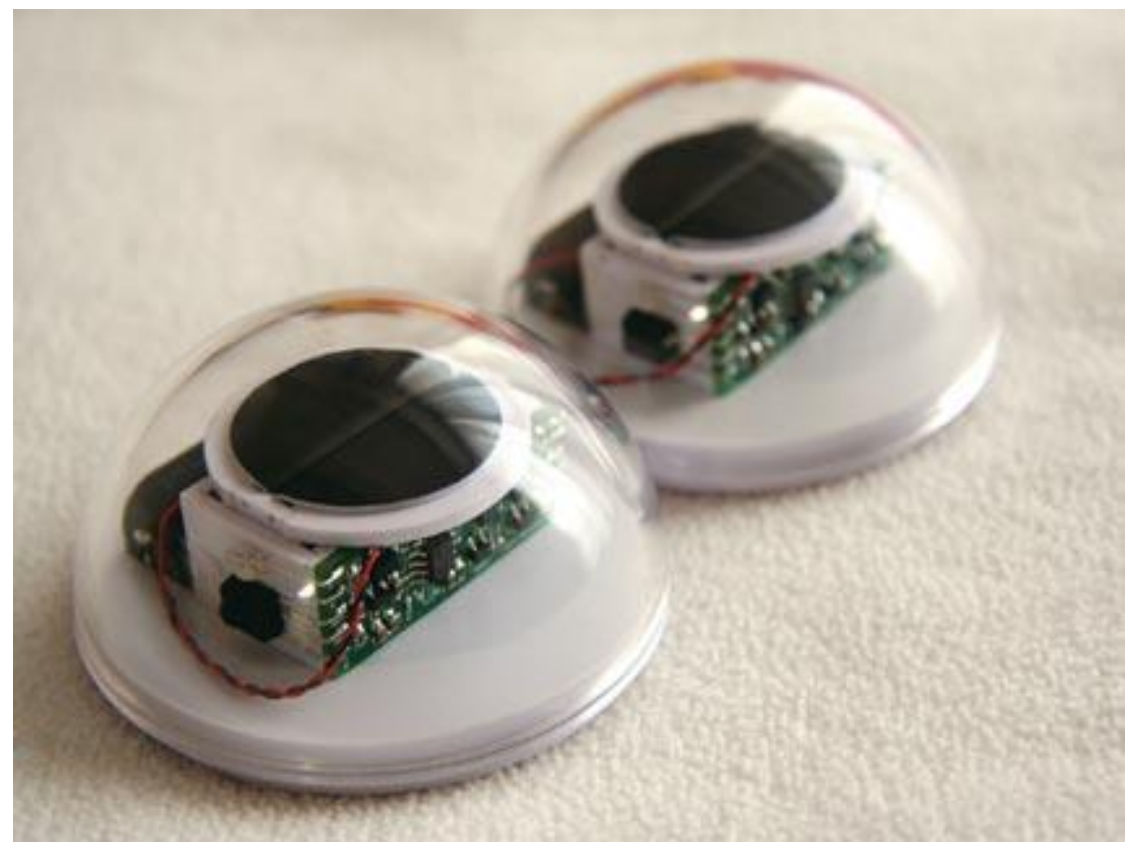

Fig.1 Ryota Kuwakubo, Nicodama, 2009, Courtesy of the artist

During the interview with the artist, Kuwakubo declared that multisensory experience of the recipient serves as one of his inspirations, whether it is a complex software or simple manual mechanism (2013). Throughout the artist's career he has transformed his artistic inspiration and slowly started to concentrate on the behavioural side of an artwork and the spectator's daily relationship with electronic devices. The continuing consideration of how people react to innovations in technology is what often motivates his creations. The artist is interested in the whole bodily experience and multimodality of it; every aesthetic experience cannot be removed from its multisensory aspect. The experiences being 
provided by technologically aided artworks are at the core of his works, establishing communications between people and machines. The physical engagement in order to complete the artwork is at the core of the concept.

Another example of an artist who combines an interest in the human body with technologically aided objects and machines is Kumiko Kushiyama. Her engagement encapsulates all stages of creative development, from arriving at ideas to designing and engineering cutting-edge artworks and devices. Kushiyama uses hybrid practices which are neither science, engineering, nor art. In the early 2000s, her works began to oscillate predominantly between the sense of touch and different qualities of haptic experience. From the year 2003, she started developing and using tactile displays, focusing directly on a tactile interaction - like in the work Thermoesthesia, 2006.

In order to provide a whole spectrum of sensory stimuli when touching the artwork, and to give the recipient a real sense of temperature occurring in the natural world, Kushiyama uses original thermal sense-displays. This enables her to create installations which not only give the possibility to interact by touching the surface of an interface, but also to sense other haptic qualities of the given piece, such as its temperature. By adding actual thermal properties to the images representing warm or cool substances, the artist tries to recreate all the sensory features as faithfully as they occur in real life.
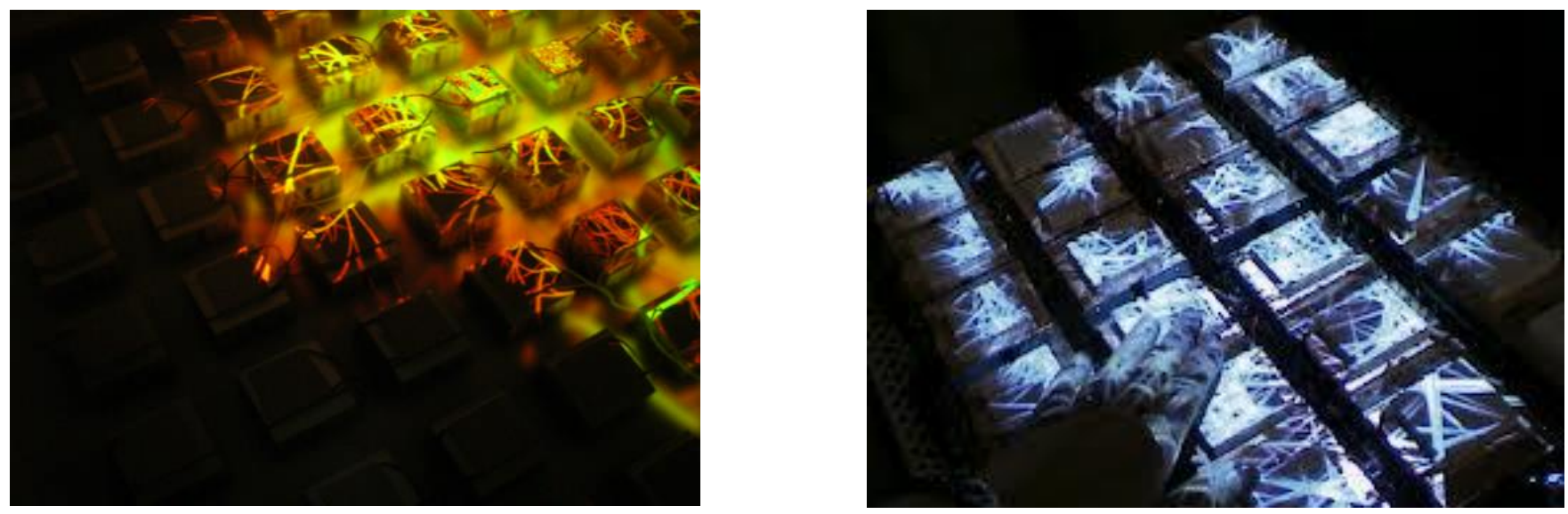

Fig. 2, 3 Thermoesthesia, 2006, Courtesy of the artist

Thermoesthesia offers recipients the opportunity to physically touch the work and experience tactile engagement, but also to directly interact with the images being part of the work. The imagery representations range from leaf-like, warmly coloured visualisations of floral patterns to cold ice crystals and snowflakes in wintry whites. The interaction with these simulated physical phenomena allows recipients to experience the natural occurrences in a different manner, in an artificially created environment, which resembles the natural one. The intention of Kushiyama is to provide the opportunity for rediscovery of the world as we know it in the immediate embodied engagement (Kushiyama 2006). The artwork encourages playful exploration of perception processes through haptic interaction between computer generated images and participants. The media construction of this work represents an attempt to engage the recipient in sensory immersion. What influences perception of this 
artwork is the fusion of the auditory and the tactile in the form of mechanical touch and temperature recognition. There is a clear reference to nature in this and other works by Kushiyama, as well as an 'organic' quality to the artwork. The discussed example serves as an indication of eastern influences declared by the artist.

In an interview with the author, Kushiyama admitted that in her opinion Japan's geographical location separates it from the rest of the developed world. In consequence, the country has been detached from any other cultural influences for a long enough time to allow Japan to develop as a culturally unique place, which is reflected in its art world. Furthermore, the artist confessed to be greatly inspired by engineering and new technologies, as well as the development of robots, humanoids and virtual reality in Japan. She uses them as stimulation for her own ideas as well as a way of implementing her creative concepts. Considering the broadly Western approaches to art, Kushiyama notices the importance of historical context, and social and theoretical background, which always appear to be an essential part of the artistic debate. In Japan, on the other hand, interactive art (and media art in general) seeks fresh, light and entertaining engagement with engineering and technological developments. It relates to the social background and the way art is valued and what is credited as art in both sides of the world.

The last example presented here is an artwork by Masaki Fujihata, who is considered one of the first artists who contributed to the instigation and establishment of interactive digital art within the framework of contemporary art. His installation Beyond Pages (1995-1997) remains the most recognisable and iconic of his oeuvre, and digital interactive artworks in general, as it serves as a classic example of interactivity in art. Beyond Pages is a digital interactive installation initially made in 1995. The artwork is created to fit into a small darkened room, in which the real interweaves with the virtual. A desk, a chair and a lamp are the actual objects in the space and a book (the actual haptic tablet) lying on the desk, is an interface between a human and a computer.

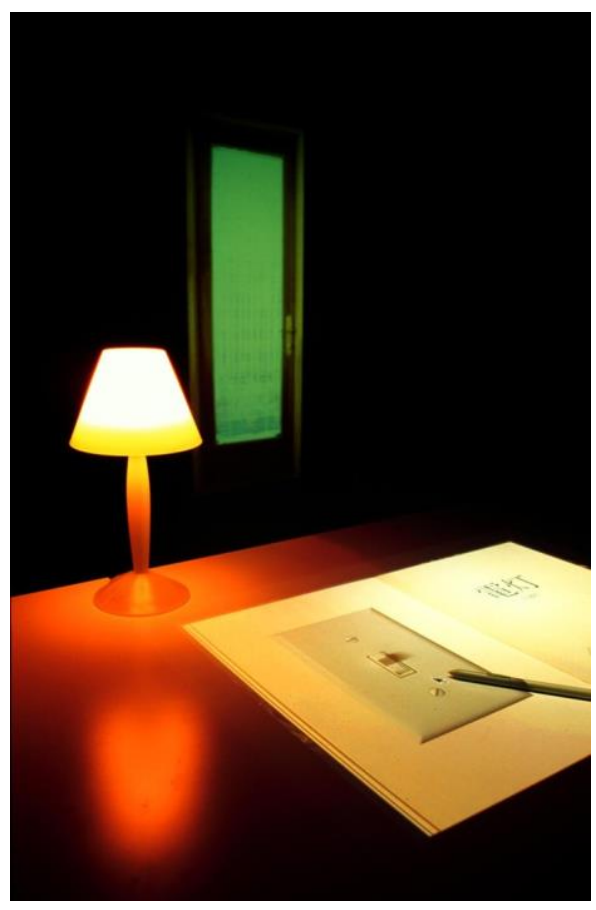

Fig. 4, Masaki Fujihata: Beyond Pages, 1995, Courtesy of the artist 
The illustrated, virtual book, just as any other, contains words and visual images. Pictures of leaves, an apple, a stone, a door, a lamp switch, an hourglass and a simple text, can be browsed through and animated with the use of a special pen - a wireless electronic device. All of this is presented as an assembly of digital images in conjunction with acoustic signals. In this work, Fujihata deals with the fusion between the real and the virtual, combining actual objects in the room with an interface and a digital projection. As a result, he creates a coherent yet hybridised environment where physical objects are blended into an imaginary world of the artist. The original function of the book is enriched with other multimodal qualities, enabling the whole body experience and cognition on many different levels. Beyond Pages requires human touch as well as involvement of the other senses. The real and the virtual are blurred and possibilities of engagement with the artwork and its main object in the form of a book are physically augmented.

It derives from an original idea of a book being an object commonly related to linear narrative, which a perceiver would ordinarily read through, in order to reveal the story. Here, an interactive book offers an alternative way of dealing with text. Every participant of this work can choose to follow a particular path of interaction. The personal reading of the interactive book, as well as the artwork's structure, are non-linear, generating tension between perception and recognition. The intention behind the artwork is to expand the possibilities of the medium and the potential of multimedia technologies in order to enable alternative ways of their use and perception. Fujihata's book in Beyond Pages is designed to exist in an interactive environment, in which reference to Umberto Eco's (1962) notion of the 'open work' is evident, and the personal interpretation is dependent on cultural context and the viewers' individual experiences. As such, nature's elements in the book can refer to animistic beliefs, or constitute yet another illustration in a picture book for others.

Like the other analysed works, it does not convey aesthetic meaning unless it is being activated, explored and perceived sensorially by participants. The role of the spectator to participate physically in the art piece and explore its hybrid potentials is at its basis dependent on implemented technology and digitally recreating human sensations. Participants are making sense of the works and experimenting with the medium using information processing systems in the form of an interactive book.

As the artist declares, there is a validation of presumption about the cultural heritage of the Japanese Edo period and a playful approach to technology (Fujihata 2013). In the Meiji period (1868-1912), the approach to many aspects of cultural and artistic spheres changed completely. Consequently, many products of creative activities, such as Ukiyo-e (Japanese woodblock prints) would be considered as 'low culture' artefacts. Following this path of reasoning, one might say that the heritage of today's digitalised and gadget-oriented culture of Japan are unavoidable concomitants of Japan's great historical-cultural past.

\section{Conclusion}

Despite the fact that in the early 1990s the focus of cultural studies shifted towards an anthropology of the senses, this area of social debate has still not taken into account the technological and scientific circumstances of artistic creativity. This reaction to the oculacentrist approach in culture aimed to transfer the foci of social sciences to more sensually versatile spheres. As asserted by Classen (1997) and Howes (2003), among others, every society has its own sensory codes and patterns, and its 
individual sensory order is manifested in material culture as artefacts, which accordingly should be examined with an appropriate attention to hybrid forms of art, culture, and media.

As observed in the above examples, media enable humans to externalise the whole central nervous system and engage physically with an artwork. Paradoxically, artworks supported by sophisticated engineering and technological developments which are based on a physical contact with machines, stimulate immediate bodily contact and awareness of its sensory modalities. The human physical body is treated as a whole and as such takes part in the aesthetic experience. Through interaction and embodied perception participants are able to observe and examine the space around them and perceive it in the most natural way with the aid of human multi-sensory properties, as well as by interaction between man and machine. Moreover, every time a human being takes part in the exploration of shared phenomena through technologically aided works, they do so from the subjective perspective of the participant. As Erkki Huhtamo puts it: "sensory perception is culturally coded" (Huhtamo 2007, 74).

Challenging as it sounds, the study of visual culture (or its counterpart/equivalent under a more suitable name) as a hybridised system, rather than as an exclusively visual category, suggests a system which would not only be focused on the image but also on art - traditional, interactive and digital art. Furthermore, one has to acknowledge a historical change in the development of a new approach to the perceptual and sensory qualities in general. Through the expansion of new technologies, human senses also extend beyond their traditional definition and play an invaluable role in the future of contemporary cultural debate. In conclusion, an effective critical understanding of particular artistic approaches to multisensory perception, and encouragement to explore culturally rooted creative practices and acknowledge sensory features of the human body in the reception of artefacts, should be taken into account when investigating sensory relations in the perception of multimodal art.

\section{References}

Arrighi, M (2011) Japanese Spell in Electronic Art, CreateSpace Independent Publishing Platform USA Ascott, R (1966) 'Behaviourist Art and the Cybernetic Vision', Cybernetica: Journal of the International Association for Cybernetics (Namur) 9(4), 247-264

Bal, M (2003) 'Visual essentialism and the object of Visual Culture', Journal of Visual Culture 2(1):523

Berque, A (1987) 'Some traits of Japanese Fudosei'. The Japan Foundation Newsletter XIV (5):1-7

Calza, G.C. (2007) in: Arrighi, Mauro, Japanese spell in Electronic Art. Kindle Edition. Accessed June 2011

Cham, K (2009) in: Digital Visual Culture: Theory and Practice, ed. A. Bentkowska-Kafel, Intellect Books, Bristol

Chang, A \& Sullivan O, C (2008) 'An audio-haptic aesthetic framework influenced by visual theory', in Antti Pirhonen \& Stephen Brewster (Eds.), Haptic and Audio Interaction Design, Springer

Chow, K. KN (2012) 'Toward Holistic Animacy: Digital Animated Phenomena echoing East Asian Thoughts', Animation 2012: 7

Classen, C. (1997) 'Foundations of the anthropology of the senses', International Social Science Journal Volume 49, Issue 153, pages 401-412, September 1997

Daniels, D (2008) 'Strategies of interactivity', in: The Art and Science of Interface and Interaction 
Design, Sommerer, $\mathrm{CH}$ et al. Springer-Verlag Berlin Heidelberg

Hansen, M.B.N and Mitchell, W.J.T (2010) Critical terms for media studies. University of Chicago Press Books

Howes, D (2003) Sensual Relations. Engaging the Senses in Culture \& Social Theory. The University of Michigan Press

Huhtamo, E (2005) Twin-Touch-Test-Redux: Media Archaeological Approach to Art, Interactivity and Tactility, in: Media Art Histories. Edited by Oliver Grau, Cambridge, Mass: The MIT Press

Huhtamo, E (2007) Intercultural Interfaces: Correcting the pro-Western Bias of Media History, conference paper at Re:place 2007. The Second International Conference on the Histories of Media, Art, Science and Technology, Berlin

Ishii, H http://tangible.media.mit.edu/ Accessed: February 2014

Eco, U (1962) The Open Work, trans. Anna Cangogni, Cambridg, MA : Harvard University Press, 1989 Eisenstadt, S.N (1995) In: Asian Perceptions of Nature: A Critical Approach, eds. Ole Bruun and Arne Kalland, 48-62. Nordic Institute of Asian Studies, Studies in Asian Topics, No. 18. Surrey: Curzon Press

Fujihata, M (2013) 'Interview with E. Sosnowska'

Kitano, N (2006) Animism, Rinri, Modernization; the Base of Japanese Robotics. In: ICRA, 07 IEEE, International Conference on Robotics and Automation, Rome, Italy, April $10-14$. www.roboethics.org, Accessed April 2014

Kluszczynski, R (2010) 'Strategies of interactive art', in Journal of Aesthetics \& Culture, Vol. 2, 2010 DOI: $10.3402 /$ jac.v2i0.5525

Kusahara, M (2001) 'Being Japanese/Being Universal- Japanese Contemporary Media Artists and the Presence of Cultural Heritage', Kobe University (Originally published in Art, Asia Pacific, 2000. This is a new version, 2001, to be published in Poland in 2002) Accessed 20. November.12 http://www.f.waseda.jp/kusahara/beingjapanese.html

Kusahara, M., (2002) 'Device Art: A New Form of Media Art from a Japanese Perspective'. Intelligent Agent. Accessed: December 2013

Kusahara, M (2006) - intelligent agent Vol. 6 No. 2, Special Issue: Papers presented at the ISEA2006

Symposium, Available online and Print-on-Demand at http://www.intelligentagent.com

Kusahara, $M$ (2008) 'Device Art? Media Art Meets Mass Production', in Troika (Ed.) Digital by

Design, Thames and Hudson. Accessed 02 February 2014

http://deviceart.vrlab.esys.tsukuba.ac.jp/Kusahara-digitaldesign.php\#fragment-12h

Kusahara, M (2013) 'Interview with E. Sosnowska'

Kushiyama, K et al (2006) Thermoesthesia: About collaboration of an artist and a scientists.

SIGGRAPH'06 Proceedings, New York

Kushiyama, K (2013) 'Interview with E. Sosnowska'

Kuwakubo, R (2009) Catalogue text: Device_art 3.009. Accessed on 12 November 2013

http://www.kontejner.org/video-bulb--nicodama-english

Kuwakubo, R (2013) 'Interview with Sosnowska'

Laurel, B (1993) Computers as theatre, Addison-Wesley Longman Publishing Co., Inc. Boston, MA, USA

Manovich, L (2003) 'New Media from Borges to HTML' in Noah Wardrip-Fruin \& Nick Montfort (ed.) Introduction to The New Media Reader, The MIT Press

Masao, y (2002) 'Karakuri: The ludic relationship between man and machine in Tokugawa Japan', in: Japan at play: the ludic and the logic of power, Joy Hendry \& Massimo Raveri (eds.), Routledge McLuhan, M (1998) The Global Village: Transformations in World Life and Media in the 21st Century, 
Oxford University Press

Marshall McLuhan (2001) Understanding Media, Routledge

Moriyama, T (2006) Curating Digital Media-Next Generation of Japanese Media Art \& Exhibition. IV 2006: 664-670, Accessed on 12 December 2012

Robles-De-La-Torre G. (2008) 'Principles of Haptic Perception in Virtual Environments' in M.

Grunwald (Ed.), Human Haptic Perception: Basics and Applications, Basel: Birkhäuser Verlag

Simanowski, R (2010) Event and Meaning: Reading Interactive Installations in the Light of Art

History. in Jörgen Schäfer \& Peter Gendolla (eds.) Beyond the Screen: Transformations of Literary Structures, Interfaces and Genres, Bielefeld

Spielmann, Y. (2012) Hybrid Culture, Japanese Media Arts in Dialogue with the West, MIT Press

Wargo, R. J.J. (1990) 'Japanese ethics: Beyond good and evil', Philosophy East and West 40 (4):499509

Yoshioka, H (1997) The Present Tense of Thought: Complex Systems, Cyberspace, and Affordance Theory, Published in Japanese

Emilia Sosnowska is a freelance curator and media researcher with a particular interest in emerging technologies and their impact on creative practices. She is currently undertaking her interdisciplinary PhD at the University of the West of Scotland. Her main research interest concerns multi-sensory experience in digital art.

Email: emila.sosnowska@gmail.com 